\title{
La reforma del servicio civil en el Estado peruano: análisis de los factores que explican los avances de un proceso que sigue constituyendo un desafío $\left({ }^{*}\right)$
}

\section{Civil Service Reform in the Peruvian State: analysis of the factors that explain the progress of a process that continues to be a challenge}

\author{
Víctor Torres Balcázar (**) \\ Ministerio de Cultura del Perú \\ ORCID: 0000-0003-0064-3543
}

Fecha de recepción: 23 de agosto

Fecha de aceptación: 13 de noviembre

ISSN en línea: $2415-2498$

Torres Balcázar, V. (2018) «La reforma del servicio civil en el Estado peruano: análisis de los factores que explican los avances de un proceso que sigue constituyendo un desafío». Politai: Revista de Ciencia Política, Año 9, segundo semestre, $\mathrm{N}^{\circ} 17:$ pp. 147-175.

DOI: https://doi.org/10.18800/politai.201802.005

\footnotetext{
* La investigación y el presente artículo van dedicados a Luciana y Josefina, mis compañeras, fuentes de motivación y razones para persistir en la mejora del sector público.

** Magíster en Ciencia Política y Gobierno con mención en Políticas Públicas y Gestión Pública, que cuenta con experiencia en diferentes entidades del Poder Ejecutivo, tales como el Ministerio de Comercio Exterior y Turismo, Ministerio de Educación, Ministerio del Interior, y Ministerio de la Mujer y Poblaciones Vulnerables. Actualmente forma parte del equipo del Viceministerio de Patrimonio Cultural e Industrias Culturales del Ministerio de Cultura. victortorresb@gmail.com
} 


\section{Resumen}

La política del servicio civil ha cumplido cinco años de implementación efectiva ${ }^{1}$ y cuenta con datos que evidencian el avance que a la fecha tiene. Precisamente, el presente artículo ${ }^{2}$ buscará abordar la fase de implementación de la citada política pública, el proceso de tránsito hacia el régimen de la Ley SERVIR, procurando proporcionar una aproximación a los resultados que hubiere arrojado este nuevo intento por iniciar una reforma en los recursos humanos del Estado peruano a partir del caso de los diecinueve ministerios ${ }^{3}$.

El análisis girará en torno a doce variables agrupadas en tres dimensiones: características organizacionales del ministerio, características de la normatividad y las herramientas del tránsito, y liderazgo en el proceso de tránsito del ministerio. Así, a partir de dichas variables, se podrá evidenciar que el grado de avance de los ministerios logra ser explicado de manera importante por la cantidad de personas que presta servicios, el tiempo que lleva el ministerio inmerso en el proceso de tránsito, la percepción de complejidad que se tiene sobre las herramientas del tránsito y la posición jerárquica de quien se desempeña como responsable organizacional del proceso de tránsito.

Los resultados de la investigación invitan a las personas interesadas en los procesos de reforma a realizar una reflexión sobre las complejidades del proceso de implementación, las alertas que la puesta en práctica lanza sobre la necesidad de aplicación de ajustes en el diseño y la pertinencia de que los actores responsables de la ejecución tomen medidas, mientras la política en cuestión sea legítima y visible. Aquellos aspectos cobran particular importancia para la reforma en cuestión, toda vez que han transcurrido cinco años desde la publicación de la primera versión con los pasos que deberían guiar el tránsito de las entidades públicas al régimen del servicio civil y que, hasta la fecha, solo una entidad estatal ha logrado concluir con dicho proceso.

Palabras clave: reforma, servicio civil, función pública, modernización, Servir

\footnotetext{
1 Para la presente investigación se deberá comprender por 'un año de implementación efectiva' al periodo que ha transcurrido desde la publicación de los "Lineamientos para el tránsito de una entidad pública al régimen del servicio civil", mediante Resolución de Presidencia Ejecutiva № 160 2013-SERVIR/PE, en octubre de 2013 hasta la fecha de elaboración de este documento.

2 El presente artículo resume la investigación realizada entre el 2015 y el 2016 para la elaboración de la tesis de postgrado que condujera a la obtención del grado de magíster, cuya versión completa se encuentra disponible en el siguiente enlace web: http://tesis.pucp.edu.pe/repositorio/handle/123456789/8124

${ }^{3}$ En el caso peruano los ministerios son diecinueve: Ministerio de Agricultura (MINAGRI), Ministerio del Ambiente (MINAM), Ministerio de Economía y Finanzas (MEF), Ministerio de Comercio Exterior y Turismo (MINCETUR), Ministerio de Cultura (CULTURA), Ministerio de Defensa (MINDEF), Ministerio de Desarrollo e Inclusión Social (MIDIS), Ministerio de Educación (MINEDU), Ministerio de Energía y Minas (MEM), Ministerio del Interior (MININTER), Ministerio de Justicia (MINJUS), Ministerio de Salud (MINSA), Ministerio de la Mujer y Poblaciones Vulnerables (MIMP), Ministerio de la Producción (PRODUCE), Ministerio de Relaciones Exteriores (RREE), Ministerio de Salud (MINSA), Ministerio de Trabajo (MTPE), Ministerio de Transportes y Comunicaciones (MTC), Ministerio de Vivienda, Construcción y Saneamiento (MVCS) y la Presidencia del Consejo de Ministros (PCM).
} 


\begin{abstract}
Civil service policy has fulfilled five years of effective implementation and its progress until the present is evidenced by available data. This article seeks to address the implementation phase of the aforementioned public policy, the process of transit to La Ley SERVIR regime's, and tries to provide an approximation of the results that this new attempt to start a reform in the human resources of the Peruvian State would have had, following the case of the nineteen ministries.
\end{abstract}

The analysis will have as its central core twelve grouped variables in three dimensions: organizational characteristics of the ministry, characteristics of the legal norms and tools of transit, and leadership in the transit process of the ministry. Thus, considering those variables, we argue that the degree of progress of the ministries is explained in an important way by the number of people that provide their services, the time that the ministry takes in the process of transit, the perception of complexity that one has about the tools of transit, and the hierarchical position of those in charge of the transit process.

Our results invite to reflect on the complexity of the process of public-policy-implementation, the need to apply adjustments to the initial design and the relevance of the actions taken by those involved in the execution process, as long as the aforementioned policy is legitimate and visible. Those aspects are important for the reform. Five years have passed since the publication of the first version with guidelines for the transit of public entities to the civil service regime and, until the present, only one entity of the Peruvian State has managed to conclude the process.

Keywords: reform, civil service, public function, modernization, Servir 


\section{Antecedentes}

La modernización de la gestión pública es un área temática que ha congregado diferentes esfuerzos en el Estado peruano desde la segunda mitad de la década del noventa. Ello tras el reconocimiento, bajo la influencia de las reformas de segunda generación (Bresser Pereira, 1998, pp. 539-540), de que las medidas implementadas en materia de política económica y monetaria no eran suficientes para garantizar el crecimiento económico del país y la reducción de sus principales problemas sociales y que, por consiguiente, resultaba necesario replantearse nuevamente el rol del Estado y el papel que en él jugaba la burocracia.

En esa línea, el concepto 'Estado', aterrizado sobre el de 'administración pública', como el conjunto de entidades públicas que lo conforman y a través de las cuales produce bienes y presta servicios en atención a proyectos y políticas que debieran estar articulados, empezó a concitar la atención de algunos sectores de la administración de turno. Se reconocía que el desempeño de las entidades públicas y, por consiguiente, el de los servidores públicos, incidía en diferentes características de los bienes y servicios que ofertan, lo que a su vez afectaba la valoración que el individuo le otorga a dichos productos en su rol de ciudadano, cliente o usuario. Con ello, las alternativas de solución en discusión pasaban de girar en torno a la disminución del papel de la burocracia estatal, al análisis del rol estratégico de la administración pública y de la orientación de su accionar hacia los individuos en su rol de ciudadano, cliente o usuario.

Sin embargo, los esfuerzos por mejorar la gestión pública en el Estado peruano no respondían a una política integral, sino a iniciativas aisladas y poco coordinadas entre sí. Más allá del surgimiento y fortalecimiento de algunas entidades, que hasta la fecha son referentes en materia de modernización de la gestión pública, no se logró que el Estado en su conjunto evidenciara la implementación de una política nacional de modernización.

Sería recién tras el gobierno de transición, que las administraciones de turno empezarían a configurar un marco normativo, como parte de un diseño real de una política pública sobre modernización, para sentar las bases de líneas de acción coherentes que alcancen a todas las entidades del Estado. Así, inicialmente con una Ley aprobada en el 2002 y varios años después con su desglose en un Decreto Supremo en el 2013, que esbozaba una política más concreta, el Estado, atravesando a tres gobiernos, daba paso a la fase de implementación de una política pública sobre modernización de la gestión pública.

No obstante, en paralelo a ese trabajo de creación normativa, lo que la realidad reflejaba era que el periodo de bonanza económica ${ }^{4}$ por el que se estaba atravesando no iba acompañado de un crecimiento similar de la capacidad estatal para administrar los mayores recursos ${ }^{5}$. Esa situación se tornaba más visible al contrastar el crecimiento anual del presupuesto público con los niveles promedio de gasto público, sobre todo para el caso de los niveles regional y local. Ese contexto favorable, aunque inadecuadamente aprovechado, llevó a poner en agenda la urgencia de introducir

\footnotetext{
${ }^{4}$ Los porcentajes más altos de crecimiento del Producto Bruto Interno (PBI), desde el retorno de la democracia, lo han tenido los gobiernos de los presidentes Alejandro Toledo y Alan García. Así, la gestión de Toledo cierra el año fiscal 2006 con un crecimiento del 7.7\%, mientras que García hace lo propio en el 2011 con un crecimiento del 6.9\%. En ambos casos, dichos años, a su vez, representaron los años de gobierno en el que mayor presupuesto público se asignó. De un lado, durante la gestión de Toledo el Presupuesto Institucional de Apertura (PIA) del 2006 fue de más de 45 mil millones de nuevos soles ( $21 \%$ más que el presupuesto con el que inició su gestión), mientras que, del otro, la gestión de García asignó para el 2011 un PIA de más de 88 mil millones de nuevos soles (34\% más que el presupuesto con el que inició su gestión).

$5 \mathrm{El}$ indicador que mejor grafica dicha premisa es el porcentaje de ejecución del presupuesto público. En esa línea, y tomando como referencia el periodo 2006 - 2010, que es el que concentra los niveles más altos de crecimiento del PBI, se tiene que el promedio del nivel de ejecución del presupuesto público en los niveles regional y local fue, en promedio, de $80.02 \%$ y $68.02 \%$, respectivamente.
} 
nuevas reformas de segunda generación e implementarlas de manera progresiva sin posibilidad de esperar que la política pública de modernización de la gestión pública transite de su fase de diseño a la de implementación.

La necesidad de eliminar barreras burocráticas, volver más efectivos los mecanismos de recaudación tributaria, mejorar la ejecución del gasto público, entre otras soluciones identificadas para combatir el problema del desaprovechamiento del crecimiento económico, iban asociadas a la urgencia de potenciar el capital humano del sector público: los ejecutores de las acciones públicas. Todas esas soluciones propuestas, incluida la del servicio civil, se volvieron objetivo de reformas en la última década, siendo abordadas por las administraciones de García Pérez y Humala Tasso en diferente medida.

Así, a mediados del 2008, apelando a la Reforma del Estado, el gobierno de turno formalizó el inicio de la etapa de diseño de uno de los pilares de la modernización de la gestión pública: la política pública sobre servicio civil. La intención de esa política era complementar el crecimiento económico sostenido del país con el crecimiento de las capacidades estatales, aprovechando la ventana de oportunidad generada por la firma del Tratado de Libre Comercio con los Estados Unidos para promulgar un paquete normativo sobre gestión de los recursos humanos en el Estado.

Tras la desactivación del Instituto Nacional de Administración Pública en los noventa no hubo intervención pública relevante en materia de recursos humanos. La creación del ente rector del sistema administrativo de gestión de recursos humanos significó el retorno de los esfuerzos por administrar el servicio civil peruano y construir una carrera pública. De cierto modo, la creación de un rector en materia de recursos humanos respondía a la ausencia de institucionalidad para retomar el diseño de una política pública de esa naturaleza:

La Administración Pública no solo está constituida por los entes que prestan servicios públicos. Una parte fundamental (que, por demás, tiende a adquirir creciente relevancia) es la institucionalidad dedicada a la formulación de las políticas públicas y a las actividades de rectoría y regulación. Pero, para los entes regulatorios las propuestas realmente innovadoras son escasas; para aquellos que constituyen el núcleo estratégico del Estado son casi inexistentes. Tal vez ello se explica porque las prescripciones en boga emergen de países donde este tipo de institucionalidad funciona «bien». Pero este no es el caso de América Latina, donde un déficit central atañe al propio modelo burocrático. El corporativismo y el clientelismo constituyen una expresión de este déficit. No dar cuenta de ellos puede aumentar tales problemas (Cunill 1999: 15 - 16).

Sin embargo, más allá de la creación de un grupo de gerentes públicos seleccionados de manera meritocrática y puestos a disposición de la demanda de las entidades públicas, y de la implementación de algunas prácticas novedosas en materia de gestión de las necesidades de capacitación de los servidores públicos, no se produjeron cambios trascendentales en los primeros cinco años de existencia de dicho ente rector, lo que coincide con el modelo de una política incrementalista.

Es en el año 2013 cuando la política del servicio civil se posiciona como una de las políticas públicas más representativas del presente decenio, tras la publicación de la Ley $\mathrm{N}^{\circ}$ 30057, Ley del Servicio Civil, a mediados del citado año, y de sus Reglamentos tan solo un año después. Con ello no sólo recobraba relevancia en la agenda pública el tema de la gestión de los recursos humanos, sino que se potenciaba en sí mismo, al volver obligatoria la adecuación de las entidades públicas a unos 
lineamientos en materia de modernización y esbozar lineamientos generales sobre carrera pública, capacitación, directivos públicos, evaluación del desempeño, entre otros asuntos.

Así pues, el diseño de la política del servicio civil asumía el supuesto de que, “(...) si la institucionalidad pública es el marco de incentivos de las organizaciones públicas, cualquier reforma de estas sólo será positiva y duradera en la medida en que contribuya a reformar también positiva y duraderamente el fondo o marco institucional en que la organización se inserta. Toda verdadera reforma del Estado ha de ser, pues, a la vez, organizativa e institucional" (Cunill, 1999, pp.15 - 16).

\section{La reforma del servicio civil en el Perú}

Hasta antes de la publicación del Decreto Legislativo $\mathrm{N}^{\circ} 1023$, que crea la Autoridad Nacional del Servicio Civil, no se habían dado más que muestras de preocupación por el desorden imperante en torno a la gestión de los recursos humanos en el Estado, y algunos intentos aislados por aminorar el caos de la convivencia de múltiples regímenes laborales y resolver el congelamiento de las remuneraciones.

Es con la creación de SERVIR que se instala en el Estado peruano una preocupación por iniciar una real reforma del servicio civil, indistintamente de los gobiernos que empezarían a transitar. A todas luces, el nuevo ente rector del sistema administrativo no iba a poder abordar las diferentes causas y subcausas del problema, por lo que, bajo un enfoque incrementalista, se optó por concentrar esfuerzos en la formación de un Cuerpo de Gerentes Públicos, tomando como ejemplo la experiencia chilena con los directivos públicos. La primera Presidenta Ejecutiva de SERVIR da más detalles sobre los pasos iniciales:

Las primeras decisiones buscaron mostrar avances que respaldaran aquellas que se habrían de tomar en el futuro. De hecho, el Consejo Directivo apostó a la convocatoria de la primera promoción de gerentes públicos mientras los demás equipos de SERVIR se constituían y fortalecían. La decisión se basó en la constatación de que los procesos de selección podrían recaer en el sector privado, con amplia experiencia en la materia. Además, la intervención privada evitaba la injerencia política, logrando el respaldo ciudadano. Por otra parte, se asumió una política de información constante al Presidente de la República por medio de memorandos cortos y al Consejo de Ministros, de presentaciones. Ello mantuvo abierta la ventana de oportunidad y redundó en la aprobación de las normas base para los siguientes pasos de la implementación (asignación presupuestal, escala remunerativa, régimen laboral de los gerentes públicos, etc.) (Esparch 2012: 25).

Así, los primeros cuatros años de existencia de SERVIR giraron en torno al despliegue de acciones para posicionarse como ente rector del sistema administrativo frente a las oficinas de recursos humanos de los tres niveles de gobierno, desarrollar la experiencia del Cuerpo de Gerentes Públicos e intentar dar unos primeros pasos en materia de capacitación.

En paralelo, se había desarrollado un paquete normativo, que, a diferencia de los tres Decretos Legislativos promulgados por el Presidente de la República, tendría que seguir una ruta por diferentes Comisiones del Congreso. Sin embargo, la ventana de oportunidad para profundizar la reforma se había cerrado. Nuevamente el escenario político involucraba un resquebrajamiento del poder de negociación y concertación del partido de gobierno, y ello unido a la aversión de los gremios más representativos de trabajadores hacia SERVIR, desincentivaron a algunos de los 
principales voceros partidarios de asumir la promoción de la iniciativa en las Comisiones que integraban.

La transición hacia la administración de Ollanta Humala, además de una serie de cambios en la interna de SERVIR, trajo consigo un clima favorable para la revisión y ajuste de la propuesta normativa. Se retomaron los trabajos no pensando en la creación de un nuevo régimen, sino en el diseño de los cimientos para el despegue de los subsistemas de gestión de recursos humanos y en la necesidad de coordinación con el sector Economía y Finanzas para la construcción de una nueva escala de compensaciones; todo ello a la luz del trazado de una carrera pública caracterizada por la meritocracia y la potenciación capital humano.

Hacia el último trimestre del 2012 la Presidencia del Consejo de Ministros (PCM) aprueba la estrategia de modernización de la gestión pública y adquiere, nuevamente, cierta relevancia el tema de la modernización del Estado, específicamente lo concerniente a la calidad en la elaboración de bienes y prestación de servicios. Surge una nueva discusión en torno al accionar del Estado y su capacidad de satisfacer la demanda de la ciudadanía. Es así que, parafraseando a Cortázar, la búsqueda de elevar la capacidad de acción del Estado y, en consecuencia, la calidad de las políticas públicas conllevó a encontrar en un servicio civil de calidad una línea de solución que, al mismo tiempo, encerraba un proceso de reforma (2011, p. 3).

En esa línea, en un primer momento fue afinado el proyecto de Ley del Servicio Civil para su socialización con los portavoces del partido de gobierno y congresistas de otras bancadas interesados en la modernización del Estado, y, posteriormente, en coordinación con el Ministerio de Economía y Finanzas, los Reglamentos de dicha Ley. Tanto para el caso de la Ley como de los Reglamentos, el discurso asumido fue el de que "en el ámbito público, las finalidades de un sistema de gestión del empleo y los recursos humanos deben compatibilizar los objetivos de eficacia y eficiencia con los requerimientos de igualdad, mérito y neutralidad que son propios de administraciones profesionales en contextos democráticos" (Longo, 2006, p. 5).

Dicho discurso fue plasmado en el Artículo $\mathrm{N}^{\circ} 2$ de la Ley $\mathrm{N}^{\circ} 30057$, Ley del Servicio Civil, en el que se afirma que la finalidad es que "las entidades alcancen mayores niveles de eficacia y eficiencia, y presten efectivamente servicios de calidad a través de un mejor Servicio Civil, así como promover el desarrollo de las personas que lo integran" (Congreso de la República, 2013, p.1).

En el 2013, con la promulgación de la Ley SERVIR, y en el 2014 con la promulgación de los tres Reglamentos de dicha Ley, entra efectivamente en vigencia la implementación de la reforma del servicio civil. Esta reforma refuerza, a partir de un marco normativo sólido, los esfuerzos del 2008 y se sumerge en una iniciativa mucho más ambiciosa.

A la fecha, y luego del informe preparado por el Banco Interamericano de Desarrollo (BID) para el 2014, que sigue resaltando que el proceso de profesionalización de la función pública en el Perú se encuentra aún en un nivel muy bajo, SERVIR continúa con los trabajos de complementación y mejora del marco normativo a partir de directivas, instrumentos técnicos y guías metodológicas específicas que aterricen el contenido general de la Ley y sus Reglamentos; así como con las acciones de asistencia y monitoreo a un grupo importante de entidades públicas que está atravesando un proceso de adecuación para migrar al régimen del servicio civil. ${ }^{6}$

\footnotetext{
${ }^{6} \mathrm{Al} 12$ de octubre de 2018, eran 376 entidades públicas, las que se encontraban en proceso de tránsito al régimen del servicio civil. Esas, según nivel de gobierno, se distribuían de la siguiente manera: 188 entidades públicas del nivel nacional, 40 del nivel regional y 148 del nivel local. Cabe mencionar que solo una de ellas, la Oficina de Normalización Previsional (ONP), ha logrado concluir con la aplicación del total de herramientas demandadas y ya inició con los concursos públicos de méritos bajo el nuevo régimen laboral.
} 


\section{Lineamientos para el tránsito de una entidad pública al régimen del servicio civil}

En julio 2013 se aprobó la Ley N³0057, Ley del Servicio Civil, que crea un régimen único y exclusivo para las personas que prestan servicios en el Estado y que alcanza a las entidades púbicas del Poder Ejecutivo, Poder Legislativo, y Poder Judicial, a los Organismos Constitucionales Autónomos, a los Gobiernos Regionales, a los Gobiernos Locales y a los demás organismos, programas y proyectos que se consideran sujetos a las normas comunes del derecho público.

En otras palabras, en el 2013 se concretó un nuevo intento por unificar la variedad de regímenes laborales y modalidades contractuales que coexisten en el sector público, que comprende a un número aproximado de 2,500 entidades públicas que, a su vez, albergan a un total de 1’400,000 personas como servidores públicos.

\begin{tabular}{|l|c|l|c|}
\hline \multicolumn{2}{|c|}{$\begin{array}{c}\text { Total de servidores públicos según } \\
\text { nivel de gobierno }\end{array}$} & \multicolumn{2}{c|}{$\begin{array}{c}\text { Total de servidores públicos según } \\
\text { régimen laboral }\end{array}$} \\
\hline Nacional & 240,800 & DLeg. 276 & 224,000 \\
\hline Regional & 123,200 & DLeg. 728 & 98,000 \\
\hline Local & 196,000 & DLeg. 1057 & 238,000 \\
\hline
\end{tabular}

Cuadro 1. Total aproximado de servidores públicos en el Estado peruano. Elaboración propia en base a cifras de la Autoridad Nacional del Servicio Civil (SERVIR)

Esa norma se aprobó teniendo como finalidad que las entidades públicas alcancen mayores niveles de eficacia y eficiencia, y presten efectivamente servicios de calidad a través de un mejor servicio civil. Precisamente, para cumplir con dicha finalidad se apostó por un proceso de reorganización parcial de las entidades públicas, que promoviera la identificación y el aprovechamiento de oportunidades de mejora, y la justificación técnica de las reales necesidades de dotación de personal. ${ }^{7}$

En esa línea, en septiembre de 2013 la Autoridad Nacional del Servicio Civil, mediante Resolución de Presidencia Ejecutiva N ${ }^{\circ} 160-2013-S E R V I R-E^{8}$, aprobó los lineamientos para el tránsito ${ }^{9}$ de una entidad pública al régimen del servicio civil, los cuales desarrollan con mayor detalle el contenido expuesto en la Ley $\mathrm{N}^{\circ} 30057$ en materia del proceso de tránsito.

\footnotetext{
${ }^{7}$ Por 'reales necesidades de dotación de personal' se hace alusión a la determinación técnica de la cantidad de puestos y posiciones (plazas) que una organización pública requiere para llevar adelante una correcta elaboración de bienes públicos y prestación de servicios públicos, y una adecuada administración interna, así como a la especificación de las funciones, requisitos y otras características de dichos puestos que deberán tomar en consideración quienes pretendan ocuparlos.

${ }^{8}$ La citada resolución ha tenido actualizaciones casi anuales, sin embargo, las etapas que alberga no han sufrido modificaciones sustantivas, toda vez que están dispuestas de esa forma a través del articulado del Reglamento General de la Ley del Servicio Civil.

${ }^{9}$ Si bien el contenido de la Ley del Servicio Civil alcanza a la totalidad de entidades públicas citadas en líneas anteriores, hasta abril de 2016 no todas ellas estaban obligadas a implementar los lineamientos para el tránsito. En ese sentido, eran cuatro las entidades públicas exoneradas de transitar hacia el nuevo régimen del servicio civil: Banco Central de Reserva, Congreso de la República, Contraloría General de la República, Superintendencia de Administración Tributaria y Superintendencia de Banca, Seguros y AFP. Sin embargo, tras las sentencias emitidas por el Tribunal Constitucional el 26 de abril de 2016 y la Ley Nº 30647 promulgada el 17 de agosto de 2017, la Contraloría General de la República ha sido incorporada en el alcance de la Ley SERVIR.
} 
Los lineamientos se agrupan en cuatro etapas, cada una con acciones a realizar por parte de las entidades públicas llamadas a participar del proceso de tránsito. A continuación, se presenta un breve resumen por cada una de ellas:

- Etapa1. Preparación: etapa relacionada a la conformación de una Comisión de Tránsito y a la ejecución de acciones de comunicación y sensibilización del personal sobre el contenido de la Ley $\mathrm{N}^{\circ} 30057$ y la normativa asociada.

- Etapa2. Análisis situacional: etapa abocada al diagnóstico actual de puestos y procesos con la finalidad de construir una línea de base a partir de la cual identificar espacios de mejora.

- Etapa3. Mejora interna: etapa asociada a la determinación de la cantidad de puestos y de ocupantes necesarios, la elaboración de perfiles de puestos para ese total identificado y la valorización de los puestos, es decir, se procederá a la elaboración de los nuevos documentos de gestión institucional en materia de recursos humanos.

○ Etapa4. Implementación del nuevo régimen: etapa concentrada en la organización y ejecución de concursos públicos de méritos para cubrir aquellos puestos identificados como necesarios para el buen funcionamiento de la entidad.

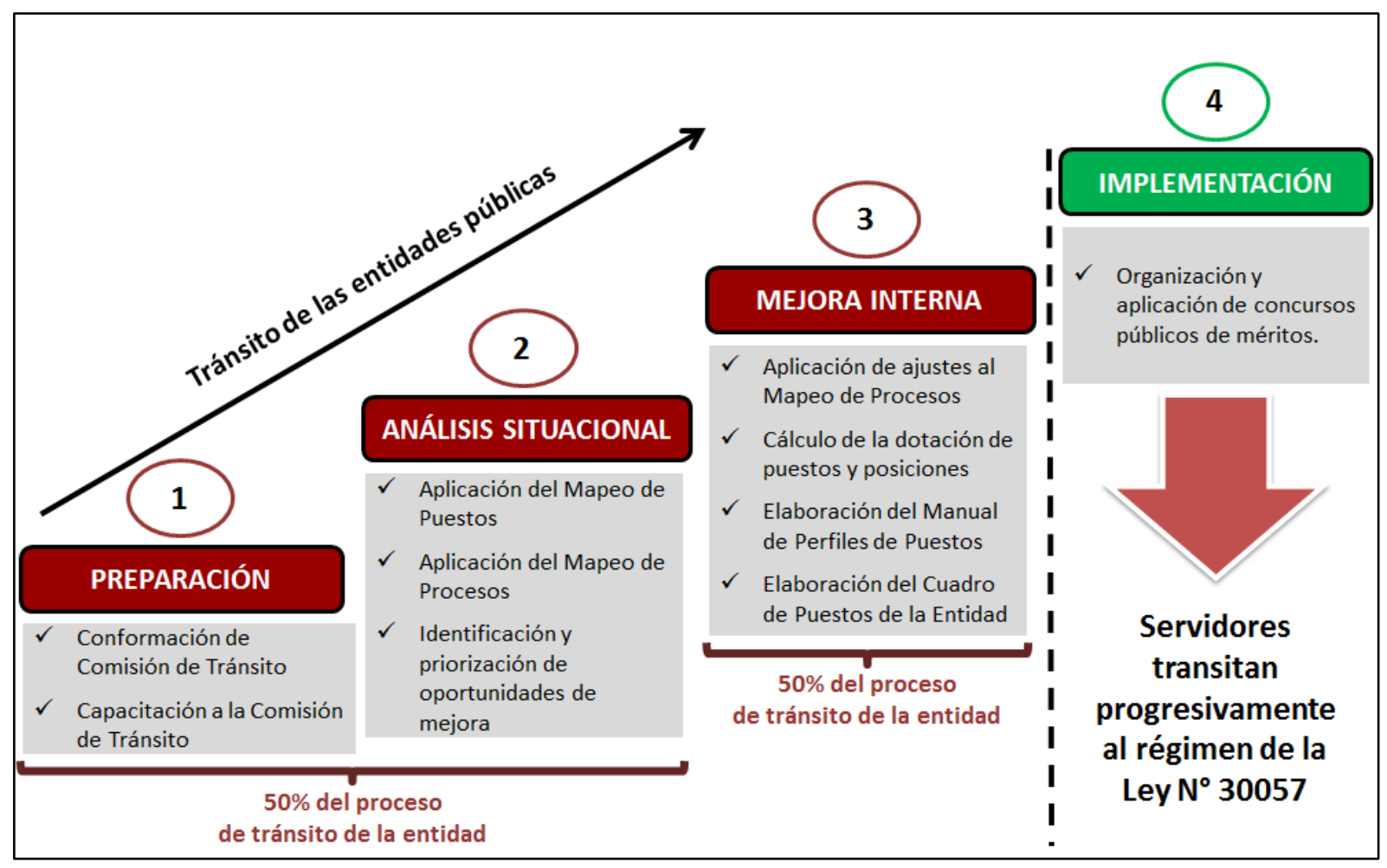

Gráfico 1. Tránsito al régimen del servicio civil. Elaboración propia en base a Autoridad Nacional del Servicio Civil (SERVIR)

El recuento de cada etapa lleva a identificar claramente que las tres primeras se concentran en la entidad pública, como organización, en tanto el trabajo gira en torno a un diagnóstico situacional y la 
posterior aplicación de mejoras en base a los resultados sistematizados; mientras que la cuarta etapa gira en torno a la incorporación de personas en los puestos señalados como necesarios a partir de la realización de concursos públicos de méritos.

Es por ello que en algunas de las entidades materia del estudio se percibía al proceso de tránsito como una oportunidad para la mejora organizacional, más allá de la realización o no de concursos públicos en el corto plazo. En esa línea, se tuvieron afirmaciones de puestos jefaturales como la siguiente:

La decisión del inicio del proceso de tránsito la tomé dentro de una coyuntura de tensión interna del ministerio. El clima era muy malo, los directivos tenían muchas quejas del rendimiento de los servidores y no había mucho que hacer (...) Entonces, es el momento en que digo 'hay que cambiar' y la única forma que había de cambiar era mirar a la nueva Ley del Servicio Civil, ver el tema de la meritocracia, ver el subsistema de gestión del rendimiento, que puede ser una herramienta que te ayude a generar ese cambio interno que se necesita. No ahora, no el próximo año, no en tres años, pero dejar instalado eso (...). Dejar sentado por lo menos las bases para que los que vengan después tengan herramientas, que yo no he tenido, y puedan mejorar la gestión (Director de Oficina de Recursos Humanos, noviembre 2015).

Es posible visualizar que la creación de un nuevo régimen laboral para el sector público, que se espera pase a convertirse en el largo plazo en el único régimen para servidores civiles, demanda, en esta ocasión, un proceso de reflexión y reorganización interna por parte de las entidades públicas previo a la realización de los procesos de selección de personal. Es ese proceso el que fue materia de análisis en la investigación para el caso particular de los diecinueve ministerios del Estado peruano.

\section{Factores que afectan la implementación de la reforma del servicio civil en los ministerios del Estado peruano}

El estudio buscó identificar cuáles eran los factores que lograban explicar el grado de implementación de los lineamientos para el tránsito de una entidad pública al régimen del servicio civil, aprobados por SERVIR, por parte de los ministerios del Estado peruano. En tal sentido, la investigación apuntó a demostrar la relación existente entre el grado de avance de los ministerios en su transición y un listado de variables agrupadas en torno a tres dimensiones: características organizacionales del ministerio, características de la normatividad y las herramientas del tránsito, y liderazgo en el proceso de tránsito del ministerio.

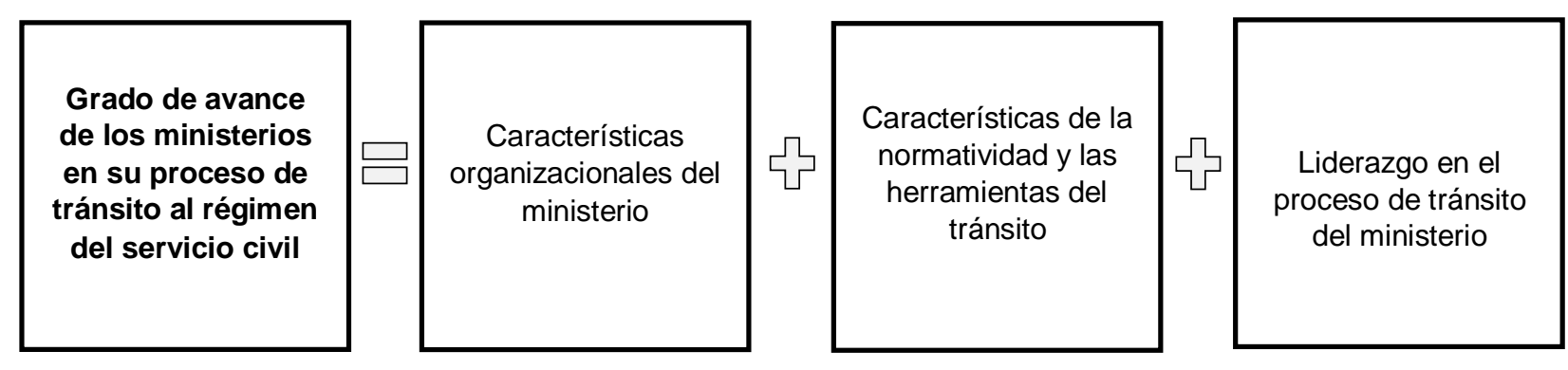

Gráfico 2. Dimensiones que afectan el grado de avance de los ministerios. Elaboración propia 
La investigación partió asumiendo la existencia de una variable dependiente y tres dimensiones con las que se relacionaba y cuyas variables independientes lograban explicarla, razón por la cual la investigación fue concebida como de tipo explicativa. La selección de dichas variables independientes estuvo condicionada a la existencia de datos confiables, el acceso a las fuentes de

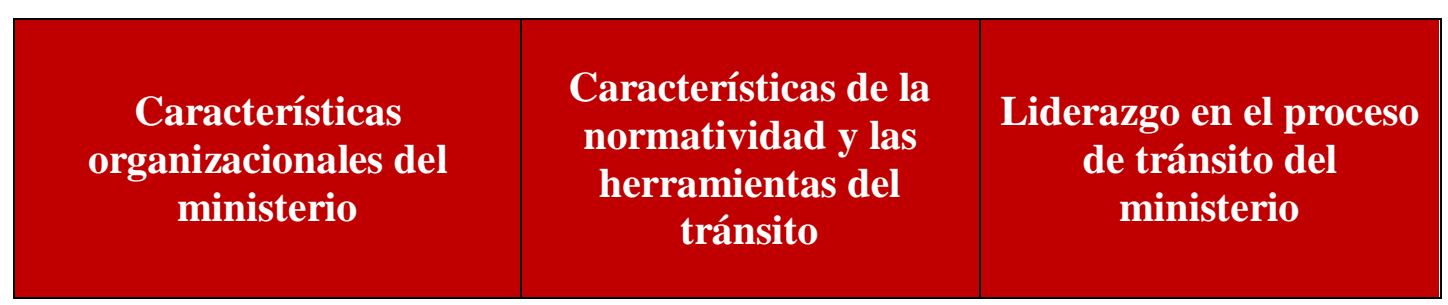

información identificadas y la posibilidad de incluirlas en un modelo econométrico simple.

En esa línea, se lograron identificar doce variables, las cuales pasan a ser enunciadas en el siguiente cuadro: 


\begin{tabular}{|c|c|c|}
\hline $\begin{array}{l}\text { Cantidad de personas que } \\
\text { han asumido la titularidad } \\
\text { del ministerio }\end{array}$ & $\begin{array}{l}\text { Cantidad de años que } \\
\text { lleva en tránsito el } \\
\text { ministerio }\end{array}$ & $\begin{array}{l}\text { Posición jerárquica del } \\
\text { puesto que se desempeña } \\
\text { como ‘champion' en el } \\
\text { ministerio }\end{array}$ \\
\hline $\begin{array}{l}\text { Cantidad de personas que } \\
\text { prestan servicios en el } \\
\text { ministerio }\end{array}$ & $\begin{array}{l}\text { Organización de la } \\
\text { operatividad del tránsito }\end{array}$ & $\begin{array}{l}\text { Posición jerárquica del } \\
\text { puesto que se desempeña } \\
\text { como 'process leader' en }\end{array}$ \\
\hline \multicolumn{3}{|c|}{ Nombre de variables independientes } \\
\hline $\begin{array}{l}\text { Cantidad de regímenes } \\
\text { laborales y modalidades } \\
\text { contractuales que coexisten }\end{array}$ & $\begin{array}{l}\text { Percepción de la } \\
\text { complejidad de las } \\
\text { herramientas del tránsito }\end{array}$ & - \\
\hline $\begin{array}{l}\text { Proporción de ocupantes de } \\
\text { puestos en regímenes } \\
\text { laborales permanentes }\end{array}$ & - & - \\
\hline $\begin{array}{l}\text { Grado de injerencia de los } \\
\text { sindicatos en los asuntos } \\
\text { vinculados al tránsito del } \\
\text { ministerio }\end{array}$ & - & - \\
\hline $\begin{array}{l}\text { Rotación del responsable } \\
\text { del órgano o unidad } \\
\text { orgánica de planeamiento y } \\
\text { presupuesto, o la que haga } \\
\text { sus veces, en el ministerio }\end{array}$ & - & - \\
\hline $\begin{array}{l}\text { Rotación del responsable } \\
\text { del órgano o unidad } \\
\text { orgánica de recursos } \\
\text { humanos, o la que haga sus } \\
\text { veces, en el ministerio }\end{array}$ & - & - \\
\hline
\end{tabular}

Cuadro 2. Distribución de las variables independientes según dimensión en la que se encuentran. Elaboración propia

Características organizacionales

Esta dimensión comprende a todas aquellas características particulares de los ministerios que podrían haber estado afectando su grado de avance en el proceso de tránsito y que, eventualmente, podrían haber sido tomadas en consideración por la administración de turno. A continuación, se listan las variables que fueron tomadas en consideración: 


\begin{tabular}{|c|l|}
\hline $\mathbf{1}$ & Cantidad de personas que han asumido la titularidad del ministerio \\
\hline $\mathbf{2}$ & Cantidad de personas que prestan servicios en el ministerio \\
\hline $\mathbf{3}$ & Cantidad de regímenes laborales y modalidades contractuales que coexisten \\
\hline $\mathbf{4}$ & Proporción de ocupantes de puestos en regímenes laborales permanentes \\
\hline $\mathbf{5}$ & Grado de injerencia de los sindicatos en los asuntos vinculados al tránsito del ministerio \\
\hline $\mathbf{6}$ & $\begin{array}{l}\text { Rotación del responsable del órgano o unidad orgánica de Planeamiento y Presupuesto, o la } \\
\text { que haga sus veces, en el ministerio }\end{array}$ \\
\hline $\mathbf{7}$ & $\begin{array}{l}\text { Rotación del responsable del órgano o unidad orgánica de Recursos Humanos, o la que } \\
\text { haga sus veces, en el ministerio }\end{array}$ \\
\hline
\end{tabular}

\section{Cuadro 3. Lista de variables específicas agrupadas en la dimensión 'características organizacionales'. Elaboración propia}

Del total de variables, se tiene que el número de personas que ocupaba puestos en los ministerios fue la variable propuesta de mayor relevancia para explicar el grado de avance del tipo de entidades seleccionado. Esa variable mostró una relación inversa con el grado de avance de los ministerios, que resultó ser relativamente fuerte, por lo que podía aprobarse la hipótesis de a mayor número de ocupantes de puestos, menor grado de avance del ministerio en su proceso de tránsito. Ello fue reforzado por el hecho de que la citada variable explicaba el grado de avance de los ministerios en un $26 \%$, tal como lo muestra el gráfico a continuación: 


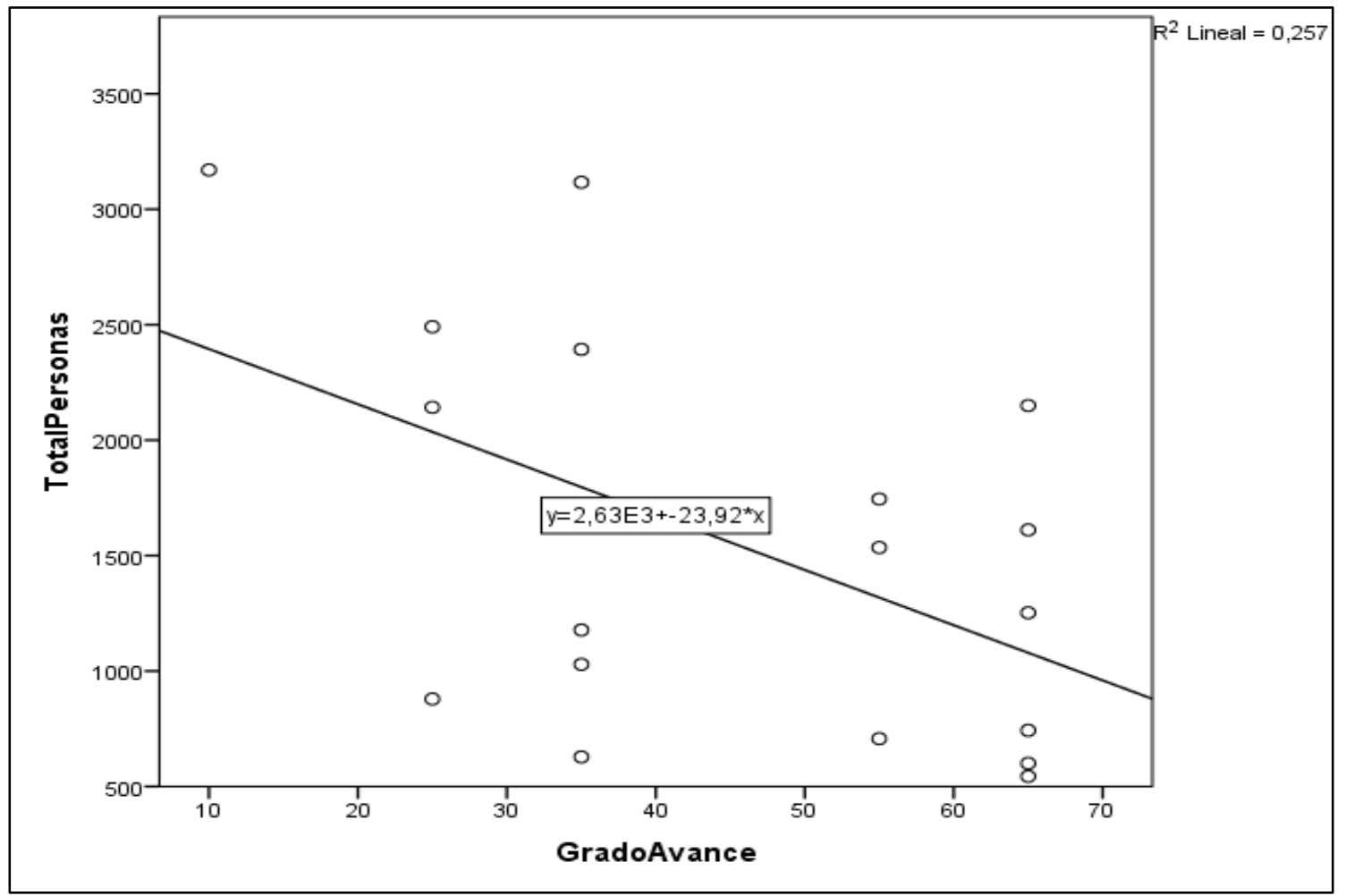

Gráfico 3. Asociación entre el número de ocupantes de puestos de cada ministerio y su grado de avance en el proceso de tránsito. Elaboración propia en base a datos de la Autoridad Nacional del Servicio Civil (SERVIR)

Sobre el total de personas que ocupaba puestos en los ministerios, se tiene que esas organizaciones, en la mayoría de los casos $(63 \%)$, contaban con más de mil ocupantes de puestos, sin embargo, la dispersión era alta, por lo que, aun cuando la media era de 1,469 personas por ministerio, la desviación estándar oscilaba alrededor de 850. Ello, dado que existían ministerios conformados por casi seiscientas personas, mientras que había otros que superan los 2,000 ocupantes de puestos.

Precisamente, es esa dispersión la que no permitía generalizar el sentido de la asociación para el caso de los diecinueve ministerios. Así, en atención a la hipótesis, ministerios como el Ministerio de Desarrollo e Inclusión Social (544), el Ministerio de Comercio Exterior y Turismo (600) y el Ministerio del Ambiente (628) deberían mostrar un grado de avance importante, en tanto eran las organizaciones con menor cantidad de personas, premisa que efectivamente cumplían en la realidad, puesto que se encontraban entre la segunda y tercera etapa del proceso de tránsito. Pero también existían casos de ministerios de grandes dimensiones, tales como el Ministerio de Economía y Finanzas $(1,611)$ y el Ministerio de Justicia $(2,150)$, que, a pesar del número mayor de ocupantes de puestos, lideraban el proceso de tránsito a nivel nacional, lo que se condecía con el tipo de asociación de las dos variables analizadas. 


\section{Características de la normatividad y las herramientas}

Esta dimensión aborda la relación entre toda aquella información sobre los instrumentos normativos y técnicos desarrollados por los actores estatales que encabezan la política pública de servicio civil y el proceso de implementación de los lineamientos para el tránsito al régimen del servicio civil por parte de los ministerios. A continuación, se listan las variables que fueron tomadas en consideración:

\begin{tabular}{|c|l|}
\hline $\mathbf{N}^{\circ}$ & \multicolumn{1}{|c|}{ Nombre de variables independientes } \\
\hline $\mathbf{1}$ & Cantidad de días que lleva en tránsito el ministerio \\
\hline $\mathbf{2}$ & Percepción de la complejidad de las herramientas del tránsito \\
\hline
\end{tabular}

Cuadro 4. Lista de variables específicas agrupadas en la dimensión 'características de la normatividad y herramientas del proceso de tránsito’. Elaboración propia

En este caso, ambas variables propuestas resultaron relevantes para explicar el grado de avance de los ministerios en su proceso de tránsito. Por un lado, el total de días que esas entidades públicas llevaban inmersas en el proceso de tránsito partía de una hipótesis bastante lógica, en tanto se presumía que los ministerios que tuvieran mayor tiempo en el proceso, contarían con más días para la aplicación de herramientas y cierre de hitos, y, por consiguiente, con un mayor grado de avance. La relación de variables mostró que, efectivamente, existía una asociación positiva y que el total de tiempo de los ministerios en el tránsito lograba explicar el grado de avance en un $25 \%$.

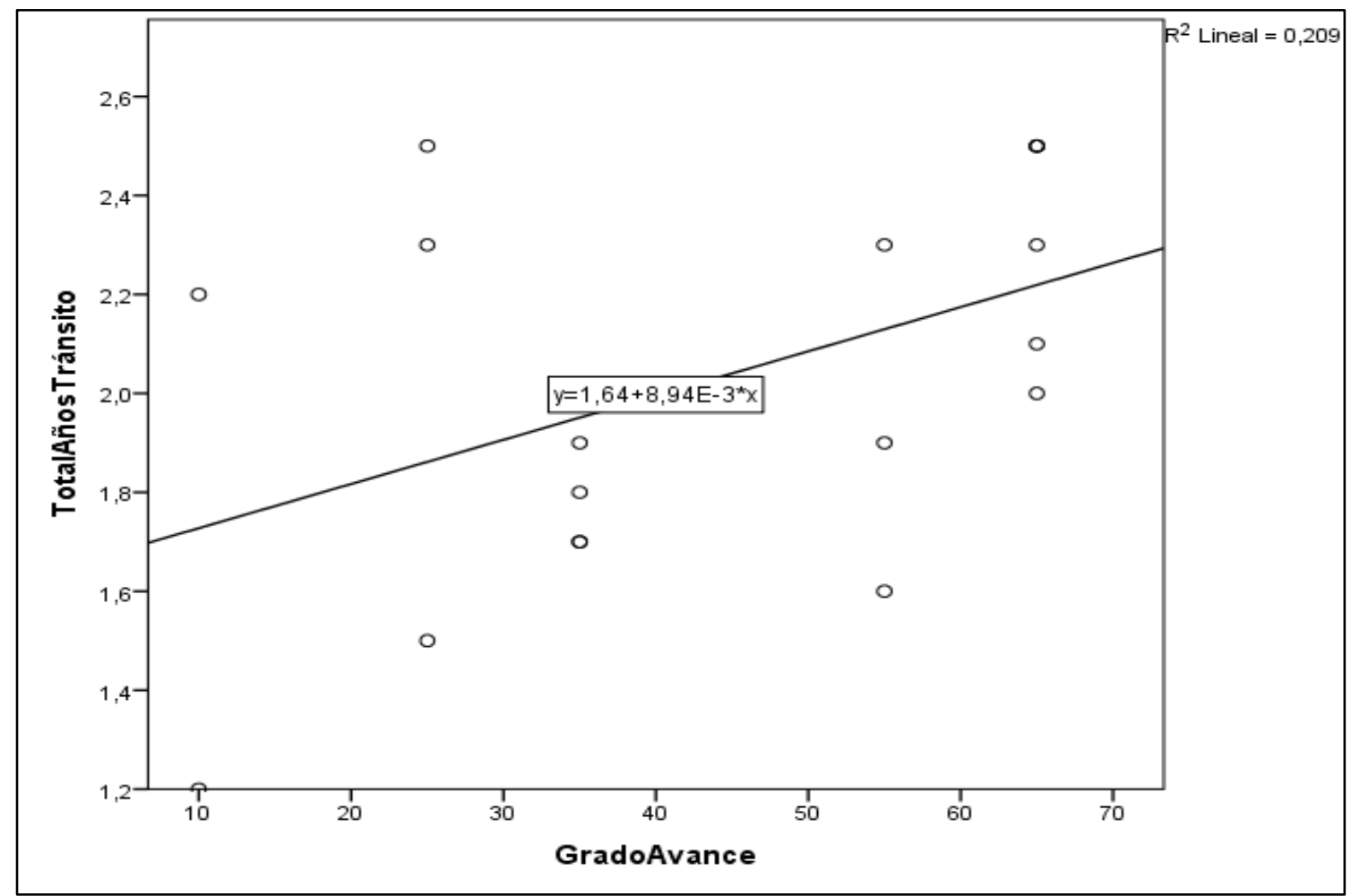

Gráfico 4. Asociación entre el total de tiempo de los ministerios del Estado peruano en el proceso de tránsito y su grado de avance. Elaboración propia en base a datos de la Autoridad Nacional del Servicio Civil (SERVIR) 
Posiblemente, la relación habría logrado ser mayor si no se presentasen casos atípicos que afectaran el grado de explicación. Así, por ejemplo, los ministerios que se encontraban en el proceso de tránsito menos de dos años presentaban una alta dispersión, con cuatro ministerios relegados y otros seis que avanzaban progresivamente hacia la mitad de la ruta del tránsito. Por su parte, el grupo de ministerios que llevaba más de dos años evidenciaba cierta uniformidad, a excepción de tres, que se encontraban ya en la tercera etapa. Lo expuesto se puede ver a más detalle en el cuadro que se presenta a continuación:

\begin{tabular}{|c|c|c|}
\hline Ministerio & Total de días & $\begin{array}{l}\text { Etapa en la que se } \\
\text { encuentra }\end{array}$ \\
\hline \multicolumn{3}{|c|}{ Más de 1 año } \\
\hline $\mathrm{PCM}$ & 438 & Etapa 1 \\
\hline MTPE & 550 & Etapa 2 \\
\hline MVCS & 599 & Etapa 2 \\
\hline MINSA & 620 & Etapa 2 \\
\hline RREE & 638 & Etapa 2 \\
\hline MINAGRI & 661 & Etapa 2 \\
\hline MINAM & 681 & Etapa 2 \\
\hline MINEM & 702 & Etapa 2 \\
\hline MIMP & 722 & Etapa 2 \\
\hline \multicolumn{3}{|c|}{ Más de 2 años } \\
\hline MINCETUR & 737 & Etapa 3 \\
\hline MIDIS & 767 & Etapa 3 \\
\hline MINEDU & 792 & Etapa 2 \\
\hline MTC & 834 & Etapa 2 \\
\hline MINDEF & 834 & Etapa 3 \\
\hline MININTER & 842 & Etapa 2 \\
\hline PRODUCE & 913 & Etapa 3 \\
\hline MINJUS & 913 & Etapa 3 \\
\hline CULTURA & 918 & Etapa 2 \\
\hline $\mathrm{MEF}$ & 920 & Etapa 3 \\
\hline
\end{tabular}

\section{Cuadro 5. Distribución de los ministerios del Estado peruano según total de días inmerso en el}

proceso de tránsito y grado de avance alcanzado. Elaboración propia en base a datos de la

Autoridad Nacional del Servicio Civil (SERVIR)

Sobre la dispersión de los tiempos invertidos, se afirmó que la razón más sólida detrás de la explicación de la demora en el tránsito de los ministerios tenía que ver con lo engorroso que resultó la tercerización de la aplicación de herramientas del proceso de tránsito, lo que llevó a que algunos ministerios recurran al apoyo de agentes cooperantes para acelerar las cuestiones administrativas:

En el mercado no es que haya empresas realmente capacitadas o especializadas (en las herramientas del proceso de tránsito). Entonces, salir por la normatividad de las contrataciones del Estado no era tan factible porque no todas las empresas tienen experiencia en el sector público, la pueden tener en el sector privado. Entonces empezamos a buscar a algunas empresas que pudieran tener una experiencia similar en el sector público, que eran pocas y, en tanto no teníamos presupuesto asignado a este tema, optamos por irnos por la cooperación internacional. Y es así que nos aventuramos a contratar por un cooperante, 
mediante el cual logramos aplicar la primera herramienta. Demoró su tiempo, pero se logró concluir con esa herramienta. Para las siguientes herramientas, partiendo del conocimiento de que no existen empresas especializadas en el sector público, iniciamos las coordinaciones con un cooperante y sale así la contratación de otra empresa (Secretario General, septiembre 2015).

Por otro lado, la investigación también consideró el supuesto de que, a mayor complejidad percibida, mayores retrasos se generarían en el proceso de tránsito de los ministerios. Así, también se identificó una asociación inversa entre dichas variables, por lo que a mayor complejidad percibida, menor grado de avance obtenido. Inclusive, se demostró que la complejidad percibida lograba explicar a la variable dependiente hasta en un $37 \%$.

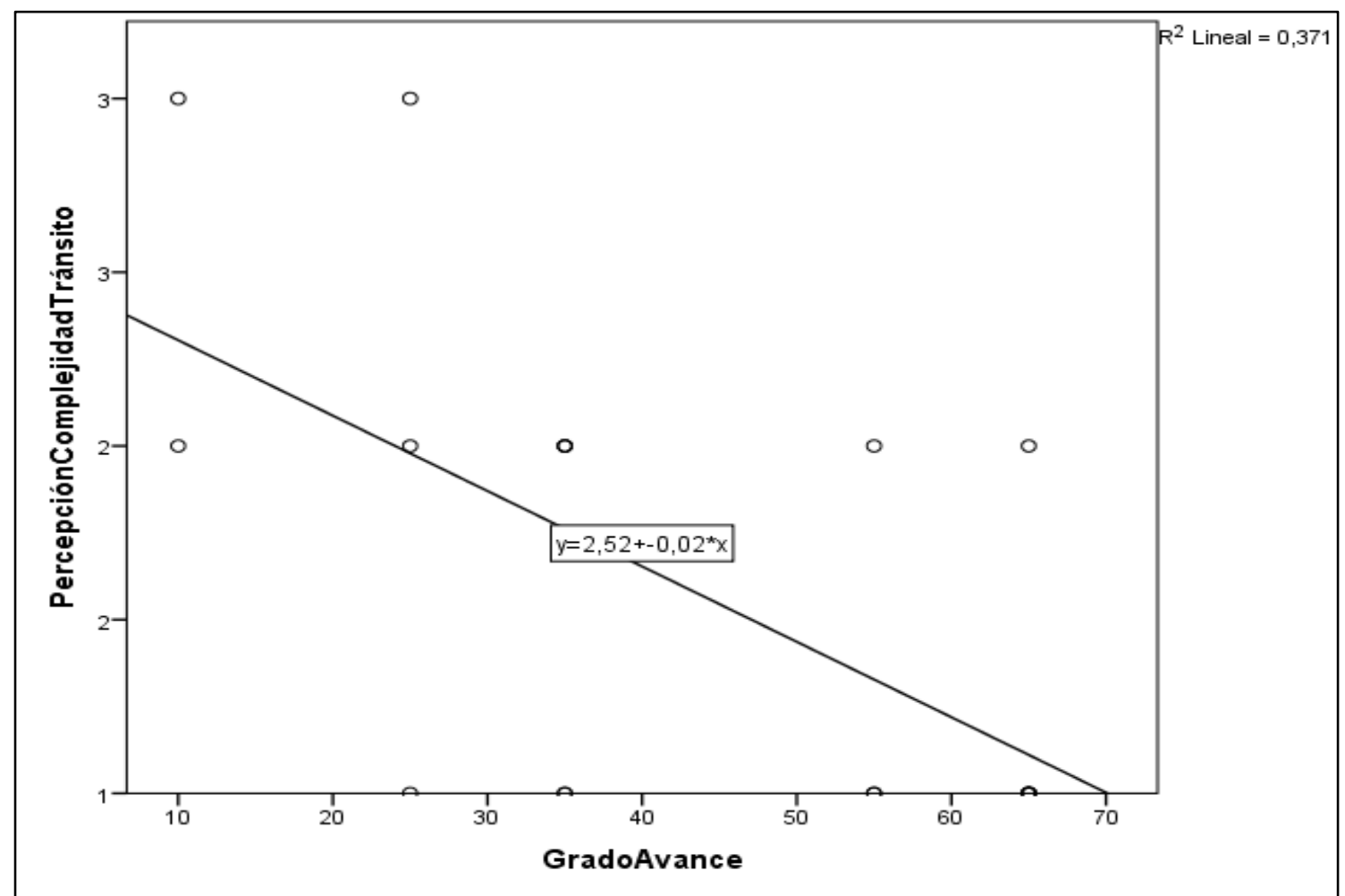

Gráfico 5. Asociación entre la percepción de la complejidad de las herramientas de del proceso de tránsito por parte de los ministerios del Estado peruano y su grado de avance. Elaboración propia en base a datos de la Autoridad Nacional del Servicio Civil (SERVIR)

Ahora bien, el grado de explicación tal vez no fue mayor debido a que la complejidad percibida fue trasladada, de cierto modo, a los consultores o empresas consultoras contratadas, de modo que los equipos de trabajo pudieran desembarazarse de cualquier dificultad. Así, más allá de concebir a las herramientas como complejas, su aplicación siguió su curso a cargo de personal externo. Sin embargo, no se debe perder de vista que, indistintamente del mecanismo de tercerización, eran las áreas usuarias las responsables de dar la conformidad a los productos entregados como parte del servicio contratado.

En esa línea, SERVIR jugó un rol importante a través del soporte a la revisión de los diferentes productos y la formulación de observaciones a las áreas usuarias, aunque en muchos casos, según lo expuesto por el equipo de asistencia técnica del ente rector, debió fungir de mediador entre los 
ministerios y las empresa consultoras, pues algunas particularidades demandadas por las herramientas no habían sido recogidas de manera satisfactoria por las consultoras y los ministerios; debido a la característica novedosa de las herramientas, no se habían percatado de los errores. Así, las rutas de aprobación de los entregables también influyeron en la extensión de los tiempos de los servicios, incrementando el total de días en tránsito de los ministerios.

\section{$\underline{\text { Liderazgo en el proceso desde los ministerios }}$}

Esta dimensión gira en torno al liderazgo ejercido al interior de los ministerios sobre la implementación de los lineamientos para el tránsito de esas entidades al régimen del servicio civil, aspecto que podría estar afectando su grado de avance en el proceso y que, eventualmente, podría ser asumido como un factor crítico a tener presente para dinamizar el ejercicio de aplicación de herramientas en ese tipo de organizaciones. A continuación, se listan las variables que fueron planteadas para ser tomadas en consideración:

\begin{tabular}{|c|l|}
\hline $\mathbf{N}^{\circ}$ & \multicolumn{1}{|c|}{ Nombre de variables independientes } \\
\hline $\mathbf{1}$ & $\begin{array}{l}\text { Posición jerárquica del puesto que se desempeña como ‘champion' en el } \\
\text { ministerio }\end{array}$ \\
\hline $\mathbf{2}$ & $\begin{array}{l}\text { Posición jerárquica del puesto que se desempeña como ‘process leader' en el } \\
\text { ministerio }\end{array}$ \\
\hline
\end{tabular}

\section{Cuadro 6. Lista de variables específicas agrupadas en la dimensión 'liderazgo en el proceso de tránsito'. Elaboración propia.}

Sobre ambas variables habría que aclarar que, si bien el proceso de tránsito parte de la conformación de una comisión integrada por los puestos jefaturales llamados a liderar la aplicación de cada una de las herramientas del tránsito y a apoyar en la solución de eventuales inconvenientes que se presenten en la implementación, ello no habría constituido una práctica recurrente.

En ese contexto, para el tránsito de los ministerios se logró identificar, en la mayoría de los casos analizados, el ejercicio de dos roles vinculados a la conducción y supervisión del proceso por parte de personas específicas que ocupan puestos situados en diferente nivel jerárquico según el ministerio del que se tratase. Es así que uno de ellos, el de 'champion' ${ }^{10}$, terminó por evidenciar la relevancia de la jerarquía del puesto que asumía la dirección general del proceso de tránsito.

En ese sentido, la figura del 'champion' era ejercida por diferentes puestos a lo largo de los diecinueve ministerios. A continuación, se muestran los diferentes niveles en los que se ubicaban los puestos que ejercían el citado rol para el proceso de tránsito en los ministerios:

\footnotetext{
${ }^{10}$ Asumiendo al proceso de tránsito como un proyecto de mejora de las entidades públicas, se vinculó la figura del ocupante del puesto preocupado por la rendición de reportes periódicos de avances e incidencias tanto del ministerio como del sector en su conjunto, y concentrado en la resolución de inconvenientes como última instancia, con la del actor conocido como 'champion' en el lenguaje de los proyectos de gestión de la calidad. En relación a esto, el 'champion' es el puesto, por lo general de la alta dirección, que monitorea a los equipos involucrados en un proyecto y juega un rol de facilitador para garantizar su correcto desarrollo.
} 


\begin{tabular}{|c|c|c|}
\hline $\begin{array}{c}\text { Nivel jerárquico del } \\
\text { 'champion' }\end{array}$ & $\begin{array}{c}\text { Etapa en la que se } \\
\text { encuentra }\end{array}$ \\
\hline Nivel 1 & CULTURA & Etapa 2 \\
\hline \multirow{4}{*}{ Nivel 4 } & PCM & Etapa 1 \\
\hline \multirow{5}{*}{ Nivel 5 } & MINJUS & Etapa 3 \\
\cline { 2 - 3 } & MINEDU & Etapa 2 \\
\cline { 2 - 3 } & MINSA & Etapa 2 \\
\cline { 2 - 3 } & MTC & Etapa 2 \\
\cline { 2 - 3 } & MTPE & Etapa 2 \\
\cline { 2 - 3 } & MIMP & Etapa 2 \\
\cline { 2 - 3 } & MINAM & Etapa 2 \\
\cline { 2 - 3 } & RREE & Etapa 2 \\
\cline { 2 - 3 } & MINEM & Etapa 2 \\
\hline \multirow{5}{*}{} & MININTER & Etapa 2 \\
\hline \multirow{5}{*}{ Nivel 6 } & MVCS & Etapa 2 \\
\cline { 2 - 3 } & MINAGRI & Etapa 2 \\
\cline { 2 - 3 } & MINCETUR & Etapa 3 \\
\cline { 2 - 3 } & MEF & Etapa 3 \\
\cline { 2 - 3 } & MIDIS & Etapa 3 \\
\cline { 2 - 3 } & MINDEF & Etapa 3 \\
\cline { 2 - 3 } & PRODUCE & Etapa 3 \\
\hline
\end{tabular}

Cuadro 7. Distribución de los ministerios del Estado peruano según nivel jerárquico del 'champion' del proceso de tránsito. Elaboración propia en base a datos de la Autoridad Nacional del Servicio Civil (SERVIR)

Los datos dispuestos evidenciaban que los casos de los ministerios en los que el rol de 'champion' era ejercido por funcionarios públicos ubicados en la alta dirección (nivel 6) representan aquellos en los que las organizaciones públicas de ese conjunto habían obtenido los mayores avances en el proceso de tránsito. Un ejemplo de ello lo describe en gran medida un funcionario de uno de los ministerios más avanzados:

Acá tenemos hasta tres grandes supervisores. La supervisión directa de la ministra, quien pide información sobre este tema, en qué estado estamos, es información cuasi diaria la que se le brinda, o, por lo menos, semanal. El otro rango de supervisión viene por el secretario general, quien ya tiene la reunión operativa, básicamente, con las personas a su cargo, que son OGA (Oficina General de Administración) y OGPP (Oficina General de Planificación y Presupuesto) en los ámbitos que corresponden. Estas dos últimas oficinas tienen a su cargo herramientas específicas, de un lado OGA con el Mapeo de Puestos, del otro lado OGPP, con el Mapeo de Procesos. Sin embargo, aunque cada oficina lidera una herramienta, ambas tienen coordinación constante. Entonces la supervisión viene desde la ministra, pasando por el secretario general y llegando hasta los directores (Secretario General, septiembre 2015).

Esto se corroboró cuando se analizaron ambas variables y se encontró que estas tenían un importante grado de asociación, lo cual indicaba que a mayor nivel jerárquico del puesto que fungía de 'champion', mayor era el grado de avance del ministerio del que forma parte. Eso quedó reforzado por el nivel de explicación que tenía esa variable sobre el grado de avance de los ministerios, que fue de $25 \%$. 


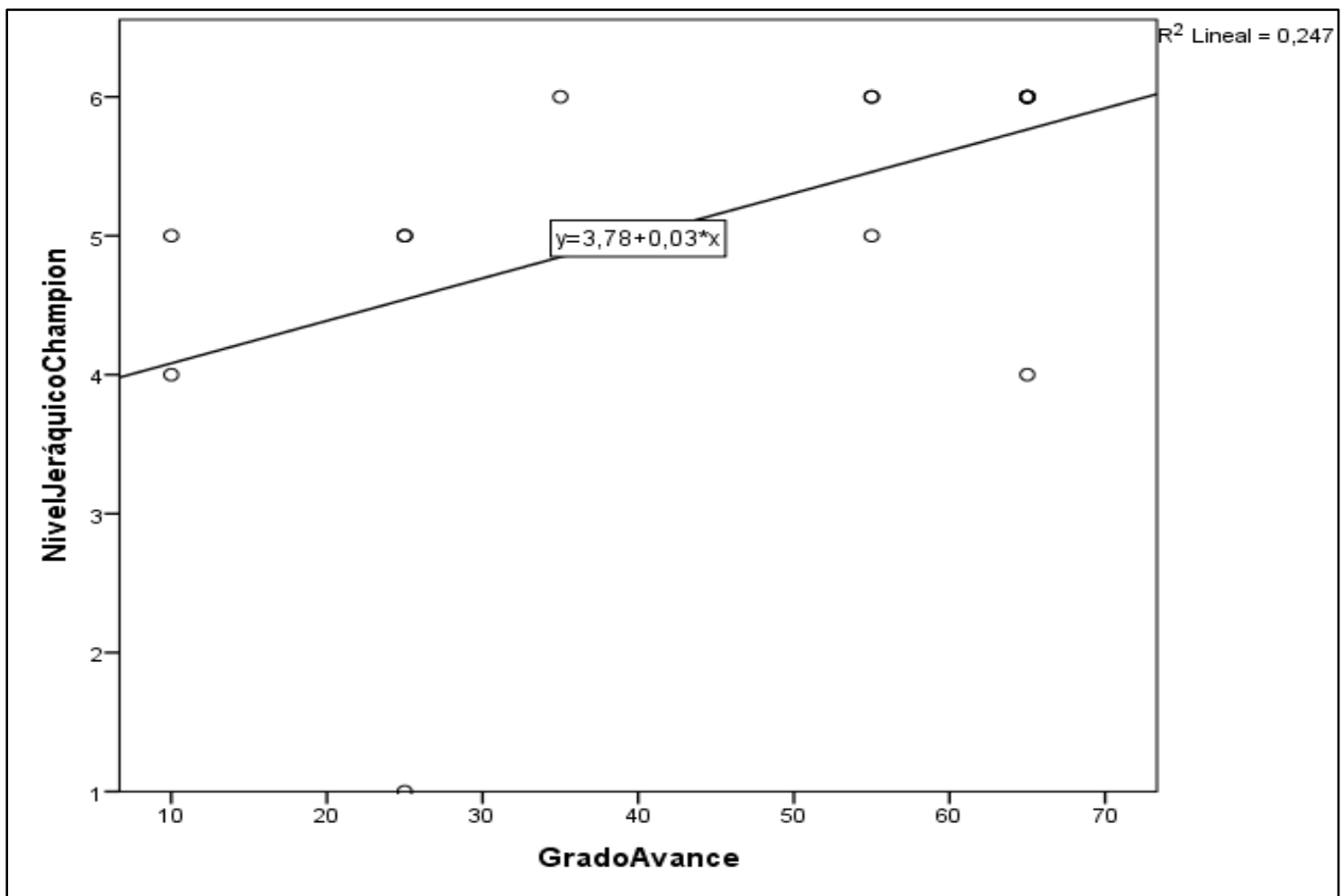

Gráfico 6. Asociación entre el nivel jerárquico del 'champion' y el grado de avance de los ministerios del Estado peruano en el proceso de tránsito. Elaboración propia en base a datos de la Autoridad Nacional del Servicio Civil (SERVIR)

Asimismo, la jerarquía del puesto que fungía de 'champion' no sólo presionaba a mantener un avance constante a las oficinas encargadas de la aplicación o supervisión de la ejecución de las herramientas de tránsito, sino que también evitaba o reducía los cuellos de botella que solían presentarse por cuestiones básicamente administrativas.

Al respecto, uno de los responsables de los órganos operativos señaló que “(...) hasta para lograr los recursos en los casos que haya que hacer consultoría, una decisión política vale más que un consenso entre planificación y presupuesto para decidir si vale la pena, o no, asignar presupuesto para contratar, por ejemplo, a una consultora. Se te puede caer el tema" (Director de Oficina de Recursos Humanos, noviembre 2015). 


\section{Análisis de los resultados}

En líneas anteriores se hizo alusión expresa al total de doce variables que se consideró originalmente como influyentes sobre el grado de avance alcanzado por los diecinueve ministerios en su proceso de tránsito al régimen del servicio civil. Sin embargo, tras el trabajo de análisis de los datos obtenidos para cada una de dichas variables se pasó a desestimar la variable 'organización de la operatividad del tránsito', en tanto la totalidad de ministerios optó por un mecanismo de implementación similar, vale decir se apoyaron en una empresa consultora o en un equipo de locadores de servicio para aplicar las herramientas del proceso de tránsito. En esa línea, la inclusión de una variable con los mismos datos en el modelo original no afectaba en lo absoluto al coeficiente de determinación resultante, razón por la cual fue retirada del análisis de la dimensión 'características de la normatividad y las herramientas de tránsito'.

Ahora, concentrándonos en las once variables finalmente consideradas se configuró un modelo que, en apariencia, explicaría el grado de avance de las organizaciones analizadas en un porcentaje notable.

\begin{tabular}{|c|c|c|c|}
\hline Modelo & $\mathrm{R}$ & $\mathrm{R}$ cuadrado & $\begin{array}{c}\mathrm{R} \text { cuadrado } \\
\text { ajustado }\end{array}$ \\
\hline 1 &, $962^{\mathrm{a}}$ & ,925 &, 789 \\
\hline \multicolumn{4}{|c|}{$\begin{array}{l}\text { a. Predictores: (Constante), NivelJerárquicoProcessLeader, } \\
\text { NivelJeráquicoChampion, TotalMinistros, PorcentajePersonaPermanente, } \\
\text { TotalAñosTránsito, InjerenciaSindicatos, TotalResponsablesOPP, } \\
\text { TotalResponsablesORH, PercepciónComplejidadTránsito, } \\
\text { TotalRegímenesModalides, TotalPersonas }\end{array}$} \\
\hline
\end{tabular}

Cuadro 8. Relación entre la variable dependiente y las variables independientes. Elaboración propia

Sin embargo, no era posible asumir que un modelo que agrupase a once variables representara un modelo fiable que permitiese explicar el avance alcanzado por los ministerios en el tránsito. Un modelo así creado arrojaba una correlación cercana al 95\%, pero ello respondía básicamente a la cantidad de variables consideradas en el modelo, por lo que en la investigación se priorizó la construcción de un modelo parsimonioso. En tal sentido, resultó apropiado proceder a limitar el grupo de variables considerado con la finalidad de construir un modelo aceptable que ayudase en la explicación de la variación del grado de avance alcanzado por los diecinueve ministerios.

A lo largo de los acápites precedentes se ha podido visualizar el porcentaje de explicación individual de las variables independientes más relevantes. Los coeficientes de determinación de la totalidad de variables pueden resumirse a través del siguiente cuadro: 


\section{Dimensiones y variables}

\section{Características organizacionales}

Cantidad de personas que han asumido la titularidad del ministerio

Cantidad de personas que prestan servicios en el ministerio

Cantidad de regímenes laborales y modalidades contractuales que coexisten

Proporción de ocupantes de puestos en regímenes laborales permanentes

Grado de injerencia de los sindicatos en los asuntos

vinculados al tránsito del ministerio

Rotación del responsable del órgano o unidad orgánica de Planeamiento y Presupuesto, o la que haga sus veces, en el ministerio

Rotación del responsable del órgano o unidad orgánica de Recursos Humanos, o la que haga sus veces, en el ministerio

Características de la normatividad y las herramientas del tránsito

Cantidad de años que lleva en tránsito el ministerio

Percepción de la complejidad de las herramientas del tránsito

\section{Liderazgo en el proceso de tránsito del ministerio}

Posición jerárquica del puesto que se desempeña como 'process champion' en el ministerio

Posición jerárquica del puesto que se desempeña como 'process leader' en el ministerio
Coeficiente de

determinación

Cuadro 9. Comparaciones entre la variable dependiente y las variables independientes. Elaboración propia

A partir de los datos presentados, se procedió a analizar en una regresión múltiple la influencia de las variables que, de manera individual, contaban con los porcentajes de explicación más altos

\begin{tabular}{|c|c|c|c|}
\hline Modelo & $\mathrm{R}$ & R cuadrado & $\begin{array}{c}\text { R cuadrado } \\
\text { ajustado }\end{array}$ \\
\hline 1 &, $855^{\mathrm{a}}$ &, 732 &, 649 \\
\hline
\end{tabular}

a. Predictores: (Constante), PercepciónComplejidadTránsito, TotalAñosTránsito, NivelJeráquicoChampion, TotalPersonas

\section{Cuadro 10. Relación entre la variable dependiente y las variables independientes.} Elaboración propia

Así, a partir de las cuatro variables que de manera individual obtenían los mayores coeficientes de determinación se llegó a la construcción de un modelo fiable que permite explicar en un porcentaje importante $(73 \%)$ a la variable dependiente. 


\section{$\mathrm{y} \square \square 6.542 \square 0.004(\mathrm{x} 1)$ 乌 $30.588(\mathrm{x} 2) \square 14.664(\mathrm{x} 3)$ 乌 $3.522(\mathrm{x} 4)$}

Donde:

- $\mathrm{y}=$ Grado de avance de los ministerios en su proceso de tránsito al régimen del servicio civil.

- $\mathrm{x} 1$ = Cantidad de personas que presta servicios en el ministerio.

- $\quad$ x2 = Cantidad de años que lleva el ministerio en tránsito.

- $\quad$ x3 = Percepción de complejidad de las herramientas del tránsito.

- $\mathrm{x} 4$ = Posición jerárquica del puesto que se desempeña como 'champion'.

\section{Gráfico 7. Modelo que explica el grado de avance de los ministerios del Estado peruano en el proceso de tránsito al régimen del servicio civil. Elaboración propia}

Vistos los resultados, se tuvo que las variables que más influían en el grado de avance de los ministerios en su proceso de tránsito al régimen del servicio civil eran la cantidad de personas que prestaban servicios en el ministerio, la cantidad de años que llevaba en tránsito el ministerio, la percepción de complejidad de las herramientas del tránsito por parte del equipo operativo y la posición jerárquica del puesto que se desempeñaba como 'champion' en el ministerio. Esas cuatro variables llevaron a tener en cuenta las siguientes afirmaciones:

- El proceso de tránsito demandaba la aplicación de herramientas que, indistintamente del modo en que son ejecutadas, requerían información por parte de los responsables de oficina y de representantes de los equipos que estos tienen a su cargo.

En esa línea, organizaciones con estructuras más grandes encerraban un mayor número de divisiones o equipos de trabajo, a lo que usualmente se le puede añadir la coexistencia de ocupantes de puestos bajo regímenes de trabajo o modalidades contractuales distintas, lo que conlleva a aplicar distintas estrategias para la aplicación de instrumentos de recojo de información. Esa complejidad de tipo operativo motivaba la extensión en el tiempo de la aplicación de las herramientas del tránsito.

- La implementación de los lineamientos para el tránsito de una entidad pública al régimen del servicio civil constituía un proceso relativamente largo que motivaba que los ministerios aplicasen una serie de herramientas para diagnosticar y resolver problemas vinculados a sus líneas operativas y a su administración interna por un periodo de casi dos años.

En ese sentido, mientras más días se encontrase un ministerio en dicho proceso, mayor sería la probabilidad de que alcance un nuevo hito que evidencie un nuevo avance, en tanto dispondría de más tiempo para organizar el proceso de contratación de un servicio de consultoría, llevar a cabo la aplicación de una de herramienta de tránsito o coordinar con el equipo responsable de SERVIR el levantamiento de observaciones para la aprobación de algún producto del tránsito.

- El modelo presentado ratificaba la lógica de que a mayor percepción de complejidad sobre las herramientas, más lento sería el proceso a ejecutar, en tanto la operatividad corría por cuenta de equipos que debían familiarizarse y aplicar lineamientos y metodologías que eran nuevas en casi toda su composición, y que les demandaban a los ocupantes de puestos una inversión adicional de tiempo y esfuerzo al usualmente destinado a las actividades propias del quehacer 
organizacional, ya sea para aplicar directamente las herramientas o para validar entregables del servicio tercerizado.

- El grado de avance del proceso de tránsito de los ministerios se vía condicionado por la posición jerárquica del puesto que se desempeñaba como ‘champion', por lo que mientras más arriba del organigrama se ubicara dicho puesto, mayor control podría ejercer en favor de la velocidad del tránsito del ministerio.

Lo antes mencionado permite afirmar que, de la totalidad de hipótesis con las que se inició el trabajo sobre los factores que podrían estar afectando el grado de avance en el proceso de tránsito, sólo cuatro de las once posibles relaciones resultaron relevantes para el problema de investigación:

- A mayor número de personas que presta servicios en el ministerio, menor será el grado de avance en el proceso de tránsito.

- A mayor número de días inmerso en el proceso de tránsito, mayor será el grado avance del ministerio en dicho proceso.

- A mayor complejidad percibida por los equipos de trabajo encargados del tránsito sobre el proceso y sus herramientas, menor será el avance del ministerio en su proceso de tránsito al régimen del servicio civil.

- A mayor jerarquía del cargo de quien está pendiente del avance general del ministerio en el tránsito, mayor será el avance de este.

Ahora, a partir del modelo construido fue posible proyectar una distribución del total de los diecinueve ministerios con las variables consideradas, lo que llevó a visualizar tres grandes agrupaciones de ministerios que merecerían algún tipo de atención especial por parte de SERVIR en pro de mantener, dinamizar o acelerar el proceso de tránsito de esas entidades públicas. 


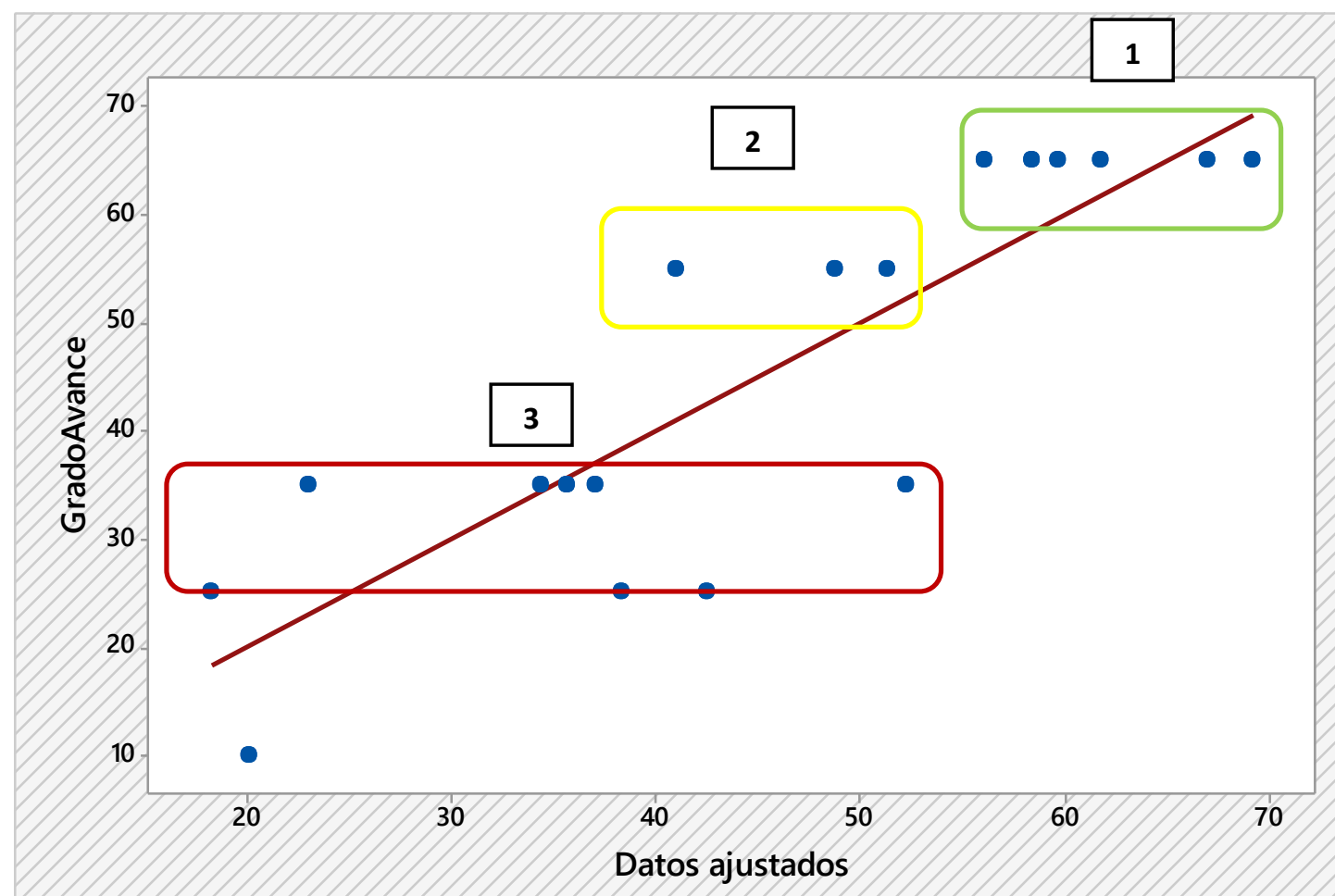

Gráfico 8. Dispersión que muestra el ajuste del grado de avance de los ministerios del Estado peruano en el proceso de tránsito al régimen del servicio

civil al modelo construido. Elaboración propia en base a datos de la Autoridad Nacional del Servicio Civil (SERVIR)

Existía un primer grupo integrado por seis ministerios (MEF, MINDEF, MIDIS, MINJUS, PRODUCE y MINCETUR) y al que se le denominó 'ministerios modelo'. Esos ministerios se caracterizaban por ser del grupo de entidades que mayor cantidad de días llevaba acumulado en el proceso de tránsito (847 días en promedio), contar con un representante de la alta dirección que demanda reportes periódicos sobre el estado del tránsito del ministerio (el ministro y/o el secretario general), poseer un equipo técnico que está familiarizado con las herramientas del tránsito y encontrarse próximos a presentar la primera herramienta de la tercera etapa del proceso de tránsito: el informe técnico que sustenta la cantidad de puestos y posiciones necesarias para el funcionamiento de la organización.

Un segundo grupo estaba conformado por tres ministerios (MINEM, MININTER y MVCS) y fue calificado como 'ministerios encaminados'. Ese grupo se distinguía por encontrarse en el tránsito por un periodo de días cercano al promedio del total de ministerios (714 días en promedio), contar con un representante de alta dirección o un directivo público al pendiente del avance del ministerio, disponer de un equipo técnico que de manera regular demanda asistencia técnica o atención de consultas especializadas a SERVIR y haber concluido con la segunda etapa del proceso de tránsito.

El tercer grupo, que concentraba a la mayor cantidad de estas organizaciones, lo integraban ocho ministerios (MINAGRI, MINAM, MINSA, MIMP, RREE, CULTURA, MTC y MTPE) y fue nombrado el de los 'ministerios vulnerables'. Ese conjunto se encontraba inmerso en el proceso de tránsito por un periodo de tiempo por debajo del promedio del total de ministerios (703 días en promedio), había tenido, en promedio, tres responsables de la Oficina de Recursos Humanos y tres responsables de la Oficina de Planeamiento y Presupuesto durante ese lapso de tiempo, no contaba con un puesto similar ejerciendo el rol de 'process leader' al interior de la organización, disponía de 
equipos de trabajo que esporádicamente establecían comunicación con el ente rector para abordar cuestiones vinculadas a la aplicación de las herramientas del tránsito y se encontraban, o bien concluyendo con la aplicación del Mapeo de Puestos, o bien ejecutando el Mapeo de Procesos.

En adición a los conjuntos presentados, había dos ministerios que no aparecían en ninguna agrupación (MINEDU y PCM). La razón de ello radicaba en que, al momento del cierre de la investigación, no se contaba con información sobre la aplicación de alguna de las herramientas del tránsito en su sede central, por lo que resultó pertinente no considerarlas, en tanto aparecían especialmente rezagadas en la distribución de los ministerios.

\section{Conclusiones}

Han pasado cinco años desde la publicación de la primera versión de los lineamientos para el tránsito de las entidades públicas al régimen del servicio civil y, según lo dispuesto en la propia Ley ${ }^{11}$, estarían restando menos de dos para la finalización de su implementación progresiva. Ello vuelve relevante la discusión en torno a la implementación del proceso de tránsito de las entidades públicas, especialmente cuando hasta la fecha solo una entidad estatal, de las 2,500 existentes, ha logrado concluir con dicho proceso.

Al respecto, la investigación realizada entre 2015 y 2016 ya adelantaba algunos resultados que delataban características organizacionales que incidían fuertemente en el grado de avance de un grupo de entidades en el proceso en cuestión. El trabajo realizado con los ministerios mostraba que el proceso de tránsito al régimen del servicio civil encerraba una complejidad propia que se potenciaba con el desorden inherente a la gestión de recursos humanos en las entidades públicas, la necesidad de un periodo de tiempo importante para familiarizarse con las herramientas y llevar a cabo la implementación progresiva, y la dependencia de un puesto de la alta dirección que motive y obligue a dinamizar la ejecución del proceso de tránsito en la organización. Además, el modelo construido les habría permitido que las entidades públicas responsables de impulsar la reforma del servicio civil planteen algunas líneas de acción customizadas a la realidad de cada ministerio, las que podrían haber acelerado la culminación de cada una de las tres etapas previas a la organización de los concursos públicos de méritos.

Sin embargo, a octubre de 2018 el panorama que cierne sobre la implementación de la política en cuestión sigue siendo similar al diagnosticado algunos años atrás, pero con el añadido de que la ventana de oportunidad que permitió su aprobación en el Congreso en el 2013 se cerró con el fin de la administración pasada, que la política pública en cuestión no cuenta con el interés del gobierno de turno y que, de existir una propuesta mejorada de diseño, el escenario político restringiría su aprobación por parte del Legislativo.

Por todo lo expuesto, aun cuando la finalidad del diseño la Ley del Servicio Civil empate con la de la política nacional de modernización de la gestión pública, su implementación viene evidenciando características que resaltan la necesidad de un periodo de años importante para aplicar los lineamientos técnicos aprobados por Servir, así como la necesidad de que ministros y/o secretarios generales se involucren en el monitoreo de dicho proceso. Todo ello en el marco de un proceso que resulta invisible a los ojos de la ciudadanía, que demanda mejoras rápidas en la prestación de los servicios públicos, con funcionarios públicos presionados para comunicar resultados de corto y

11 La Ley N 30057, Ley del Servicio Civil, publicada el 04 de julio de 2013, dispone en su Primera Disposición Complementaria Transitoria que la implementación del régimen se realiza progresivamente y concluirá en un plazo máximo de seis años. 
mediano plazo, y con una administración pública cuya mirada está encasillada en los cinco años, o menos, de duración del gobierno.

En un escenario de corto plazo con dicho grado de complejidad para la política del servicio civil lo recomendable sería, al menos, aprovechar los años restantes del gobierno de turno para identificar y plantear ajustes al diseño del tránsito de las entidades públicas, valorando e incorporando las lecciones de sus primeros cinco años de implementación y teniendo una versión expedita para aprovechar la ventana de oportunidad que abrirá el preámbulo a las celebraciones del bicentenario para propuestas serias de reforma de Estado. 


\section{Bibliografía}

Autoridad Nacional del Servicio Civil. (2010). El servicio civil peruano: antecedentes, marco normativo actual y desafíos para la reforma. Lima: Autoridad Nacional del Servicio Civil.

Autoridad Nacional del Servicio Civil. (2014). Directiva $N^{\circ}$ 002-2014-SERVIR/GDSRH. Normas para la Gestión del Sistema Administrativo de Gestión de Recursos Humanos en las entidades públicas. Lima, 3 de julio.

Bresser Pereira, L. C. (1998). "La Reforma del Estado de los años noventa: lógica y mecanismos de control". Desarrollo Económico. Buenos Aires, volumen 38, número 150, pp. 517550 .

Congreso de la República. (2004). Ley $N^{\circ}$ 28175. Ley Marco del Empleo Público. Lima, 18 de febrero.

Congreso de la República. (2012). Ley $N^{\circ}$ 27658. Ley Marco de Modernización de la Gestión del Estado. Lima, 9 de enero.

Congreso de la República. (2013). Ley N 30057. Ley del Servicio Civil. Lima, 3 de julio

Cortázar, J. C. (2011). "Aprendiendo a partir de la reforma del Servicio Civil en Chile. Algunas lecciones de interés para países latinoamericanos". Revista del CLAD Reforma y Democracia. Caracas, número 49, pp. 1-14.

Cortázar, J. C., La Fuente, M., y Sanginés, M. (2014). Al servicio del ciudadano. Una década de reformas del servicio civil en América Latina (2004-2013). Washington: Banco Interamericano de Desarrollo.

Cunill, N. (1999). "Retos de las reformas de segunda generación ¿Mercantalización y neoclientelismo o reconstrucción de la Administración Pública". Nueva Sociedad. Caracas, número 160, pp. 1-19.

Esparch, N. (2012). Ventanas de oportunidad: el caso de la reforma del Servicio Civil. Lima: Grupo de Análisis para el Desarrollo.

Iacoviello, M. (2014). Diagnóstico institucional del servicio civil en América Latina: Perú. Washington: Banco Interamericano de Desarrollo.

Iacoviello, M. (2015). Diagnóstico institucional del servicio civil en América Latina: Perú. Washington: Banco Interamericano de Desarrollo.

Longo, F. (2006). "Marco analítico para el diagnóstico institucional de Sistemas de Servicio Civil". En ECHEBARRÍA, Koldo (editor). Informe sobre la situación del servicio civil en América Latina. Washington: Banco Interamericano de Desarrollo, pp. $3-72$. Consulta: 25 de marzo de 2017. 
0situaci\%C3\%B3n\%20del\%20servicio\%20civil\%20en\%20Am\%C3\%A9rica\%20Lati na.pdf?sequence $=1$

Ramió, C. y Salvador, M. (2003). “Repensando la función pública como institución. Oportunidades y amenazas para su extensión a las realidades político-administrativas latinoamericanas". Revista Vasca de Administración Pública. País Vasco, número 651, pp. 149-175.

Presidencia del Consejo de Ministros. (2012). Decreto Supremo $N^{\circ} 109-2012-P C M$. Estrategia de Modernización de la Gestión Pública 2013 - 2016. Lima, 31 de octubre.

Presidencia del Consejo de Ministros. (2013). Decreto Supremo $N^{\circ} 004-2013-P C M$. Política Nacional de Modernización de la Gestión Pública. Lima, 11 de septiembre.

Presidencia del Consejo de Ministros. (2014). Decreto Supremo N ${ }^{\circ}$ 004-2014-PCM. Reglamento General de la Ley $N^{\circ} 30057$, Ley del Servicio Civil. Lima, 13 de junio. 